\title{
Regional oceans governance mechanisms: A review
}

\author{
Julien Rochette ${ }^{\mathrm{a}, *}$, Raphaël Billé ${ }^{\mathrm{a}}$, Erik J. Molenaar ${ }^{\mathrm{b}, \mathrm{c}}$, Petra Drankier ${ }^{\mathrm{c}}$, Lucien Chabason ${ }^{\mathrm{a}}$ \\ a Institute for Sustainable Development and International Relations (IDDRI), 27 rue Saint-Guillaume, 75337 Paris Cedex 07, France \\ ${ }^{\mathrm{b}}$ Netherlands Institute for the Law of the Sea (NILOS), Utrecht University, Achter Sint Pieter 200, 3512HT Utrecht, The Netherlands \\ ' Jebsen Centre for the Law of the Sea (JCLOS), University of Tromsø, N-9037 Tromsø, Norway
}

\section{A R T I C L E I N F O}

\section{Article history:}

Received 24 March 2015

Received in revised form

19 May 2015

Accepted 19 May 2015

\section{Keywords:}

Oceans governance

Regional seas programmes

Regional fishery bodies

Large marine ecosystems

ecosystem-based management

\begin{abstract}
A B S T R A C T
The development of regional governance for the protection of the environment, sustainable use of natural resources and conservation of its biodiversity is unquestionably a cornerstone of international environmental law and policy. With regard to marine and coastal issues, it has mainly been taking place through Regional Seas programmes, Regional Fishery Bodies and Large Marine Ecosystems mechanisms. Based on a similar geographical approach, however, these regional mechanisms raise concerns relating to their coordination and efficiency, and possibly overlap in what they aim to achieve. This paper provides a review of existing regional oceans governance mechanisms, assessing their individual and collective capacities to move towards ecosystem-based management, and highlighting options to make the regional landscape more coherent and effective.
\end{abstract}

(c) 2015 Elsevier Ltd. All rights reserved.

\section{Introduction}

The marine environment, its resources and its biodiversity are under increasing human pressure, including climate change and ocean acidification, sea-based and land-based pollution, habitat destruction, accidental or intentional introductions of alien species, over-exploitation of renewable resources and destructive fishing practises $[1,2]$. Each of these threats requires separate attention and action at all governance levels, from local to global. While dedicated policies and regulations have progressively been developed by coastal States, the last decades have shown a proliferation of multilateral environmental agreements (MEAs) which greatly help tackle oceans governance issues that require international coordination and cooperation [3].

In particular, because "not every international environmental problem needs to be dealt with on a global level" [4], the regionalisation of international environmental law and policy has emerged as one of the most important legal trends in recent years [5-7]. Compared with the global approach to oceans governance, the added value of regional oceans governance mechanisms can be summarised by the watchwords: "closer, further, faster" [8]. This regional approach has mainly been taking place within three types of regional oceans governance mechanisms: (i) Regional Seas programmes, most of which are supported or coordinated by the United Nations Environment Programme

\footnotetext{
* Corresponding author.

E-mail addresses: julien.rochette@iddri.org (J. Rochette) raphael.bille@iddri.org (R. Billé), e.j.molenaar@uu.nl (E.J. Molenaar), p.drankier@ziggo.nl (P. Drankier), lucienchabason@wanadoo.fr (L. Chabason).
}

(UNEP); (ii) Regional Fishery Bodies (RFBs), some of which have been established under the framework of the United Nations Food and Agriculture Organization (FAO); and (iii) Large Marine Ecosystem (LME) mechanisms, including projects supported by the Global Environment Facility (GEF).

Scientists have abundantly demonstrated the limits of the traditional, sectoral and essentially "issue-by-issue" approach to the threats facing the oceans [9]. There has been increasingly wide support for more holistic and integrated governance approaches that take due account of the spatial dimension and functioning of ecosystems - usually grouped under the banner of "ecosystembased management" (EBM) e.g. [10]. In conjunction, the international community has been placing ever greater emphasis on the need to rationalise and simplify the international environmental governance system, which critics deem insufficiently effective, too complex and expensive. This challenges existing oceans governance mechanisms in two key ways. First, it places their individual capacity to deliver change at the ecosystem level under closer scrutiny. The time of innocence and early enthusiasm about the simple fact that such mechanisms exist has passed. They are now required to effectively bring change in a problem-solving approach while integrating and adjusting to new and emerging concepts such as EBM. Second, complexity and costs concerns demand much higher levels of cooperation and coordination between mechanisms so as to avoid duplications and overlaps, and make the best of complementarities - in other words ensure that the whole is greater than the sum of its parts.

This paper provides a review of existing regional oceans governance mechanisms, assessing their individual and collective 
capacities to move towards EBM. It also highlights options to make the regional oceans governance landscape more coherent and effective. To that end, Section 2 first presents the key features of the three above-mentioned regional oceans governance mechanisms, while Section 3 identifies their successes and challenges. Section 4 assesses the level of cooperation and coordination among and between these mechanisms. Last, Section 5 identifies avenues for progress.

\section{Key features of regional oceans governance mechanisms}

\subsection{Regional Seas programmes}

Held in Stockholm in June 1972, the United Nations Conference on the Human Environment led to the creation of UNEP "to serve as a focal point for environmental action and coordination within the United Nations system". ${ }^{1}$ At its first session, UNEP made the oceans a priority action area ${ }^{2}$, and its Regional Seas Programme (RSP) was then initiated in $1974^{3}$ [11]. As of today, almost 150 States across 18 regions participate in the RSP (Table 1 ).

The mandates of the Regional Seas programmes cover the protection and management of the regional marine environment in the broad sense - which includes the prevention and elimination of the pollution and the conservation of marine biodiversity and apply mostly to the coastal State maritime zones of Contracting Parties ${ }^{4}$ [12]. Regional Seas programmes generally have an Action Plan which serves as the basis for regional cooperation. Moreover, 15 of them also have a framework convention complemented by issue-specific protocols. ${ }^{5}$ The framework documents - i.e. the action plan and/or the framework convention - were mostly amended in the 1990s to integrate new principles of international law which emerged with the adoption of the Convention on Biological Diversity (CBD) in 1992 and the entry into force of the United Nations Convention on the Law of the Sea (UNCLOS) in 1994. In the same way, the topics of regional protocols have expanded since the 1970s [8]. In the first phase, legal instruments organising regional cooperation to combat pollution by oil and other harmful substances from ships (Mediterranean, 1976; Western, Central and Southern Africa, 1981; Red Sea and Gulf of Aden, 1982; Caribbean, 1983; Western Indian Ocean, 1985), as well as reducing pollution from land-based sources and activities (Mediterranean, 1980; Black Sea, 1982; South-East Pacific, 1983) were adopted. This dynamic gradually expanded to encompass biodiversity conservation, particularly through the creation of marine protected areas (MPAs) (Western Indian Ocean, 1985; South-East Pacific, 1989; Caribbean, 1990). While Vallega noted in 2002 that the regional approach had "been marked by a lack of consistency of the legal framework with the prospect of operating sustainable management programmes" [13], Regional Seas protocols have, more recently but still in a limited way, taken on goals beyond the conservation of the marine environment and biodiversity, including socio-economic development. The first step in this new direction came with the adoption of the 2008 Mediterranean Protocol on Integrated Coastal Zone Management (ICZM) [14], and it is with a similar ambition that Western Indian

\footnotetext{
${ }^{1}$ UNGA, Resolution 2997 (XXVII), of 15 December 1972.

2 UNEP, Report of the Governing Council on the work on its first session, 12-22 June 1973, United Nations, New York, 1973.

${ }^{3}$ UNEP, Report of the Governing Council on the work on its second session, 1122 March 1974, United Nations, New York, Decision 8(II).

${ }^{4}$ As of today, only four regional systems - namely the Antarctic, Mediterranean, North-East Atlantic and South Pacific - have the mandate to undertake activities in ABNJ.

${ }^{5}$ There are no framework conventions and protocols in the Arctic, East Asian Seas, North-West Pacific and South Asian Seas regions.
}

Table 1

Regional Seas programmes.

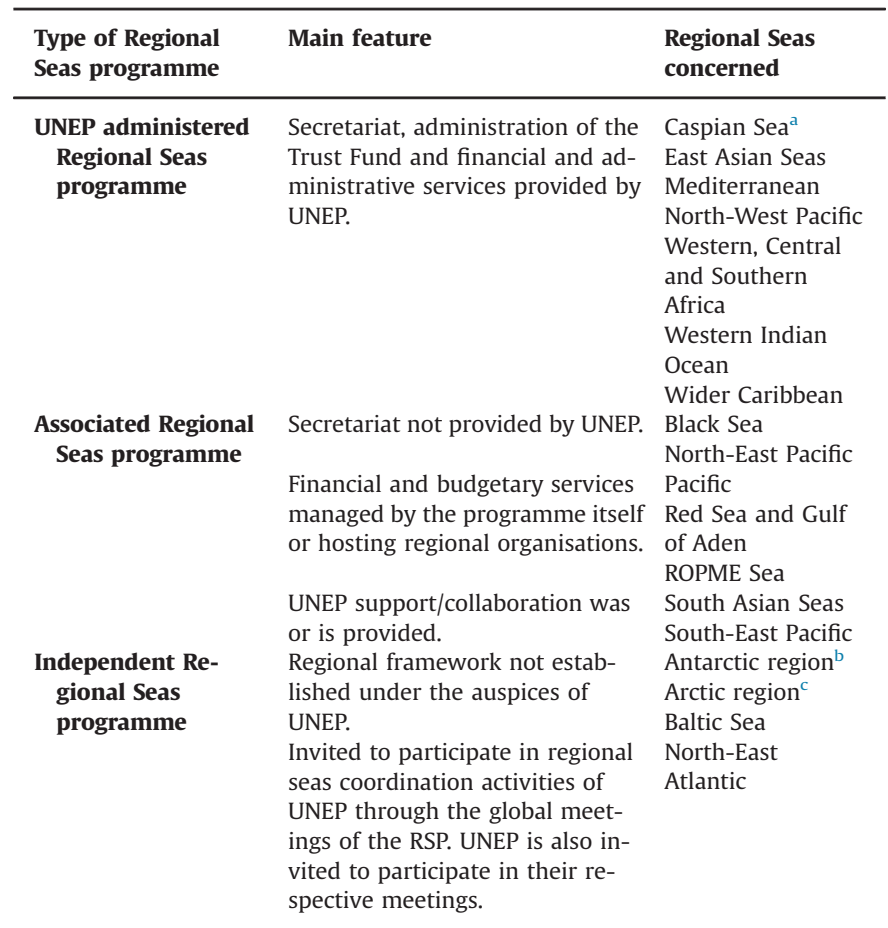

\footnotetext{
a On an interim basis, at the request of the Conference of Parties.
}

${ }^{\mathrm{b}}$ UNEP regards the Antarctic region as an independent Regional Sea programme above all on account of the 1980 Convention on the Conservation of Antarctic Marine Living Resources (CAMLR Convention), which establishes the Commission for the Conservation of Antarctic Marine Living Resources (CCAMLR). While the CAMLR Convention's objective is "the conservation of Antarctic marine living resources" (Art. II), its Preamble and many provisions indicate that CCAMLR's competence is in principle limited to fishing, associated activities, and research (e.g. Arts II(3), V, VI, IX and XXIX(1)). Moreover, FAO's RFB-list includes CCAMLR.

${ }^{\mathrm{c}}$ UNEP regards the Arctic region as an independent Regional Seas programme above all on account of the mandate and work of the Arctic Council's Protection of the Arctic Marine Environment (PAME) Working Group.

Ocean States are currently negotiating an ICZM Protocol [15].

In terms of institutional structure, all Regional Seas programmes have at least a Secretariat, called a Regional Coordinating Unit (RCU) for UNEP administered Regional Seas programmes. Some programmes also count on additional institutional structures, such as Regional Activity Centres (RACs), which play a major role by carrying out three main tasks: (i) providing States with relevant data, through publications, white papers and reports, so that they can adopt science-based decisions; (ii) strengthening regional cooperation in a specific field, by organising conferences and workshops; and (iii) providing legal and technical assistance for the implementation of conventions, protocols and action plans [16].

\subsection{RFBS}

For the purpose of this article, RFBs are defined as regional mechanisms through which States or entities (i.e. the European Union (EU) and Chinese Taipei (Taiwan)) cooperate on the sustainable use and conservation of marine living resources (fish as well as marine mammals) and/or the development of marine capture fisheries. The concept of RFBs has been used by FAO for a considerable period of time. ${ }^{6}$ Different types of RFBs exist due to

\footnotetext{
${ }^{6}$ See the information at /www.fao.org/fishery/topic/16800/en〉. Note that FAO's list of RFBs as at 17 March 2015 also includes inland waters-RFBs, the International
} 
Table 2

RFMOs and advisory RFBs. ${ }^{a}$

\begin{tabular}{|c|c|c|}
\hline RFMOs & CCSBT & Commission for the Conservation of Southern Bluefin Tuna \\
\hline \multirow[t]{4}{*}{ Tuna } & IATTC & Inter-American Tropical Tuna Commission \\
\hline & ICCAT & International Commission on the Conservation of Atlantic Tunas \\
\hline & IOTC & Indian Ocean Tuna Commission \\
\hline & WCPFC & Western and Central Pacific Fisheries Commission \\
\hline \multirow[t]{16}{*}{ Non-tuna } & CCAMLR & Commission for the Conservation of Antarctic Marine Living Resources \\
\hline & CCBSP & Convention on the Conservation and Management of Pollock Resources in the Central Bering Sea \\
\hline & CTMFM & Joint Technical Commission of the Maritime Front \\
\hline & GFCM & General Fisheries Commission for the Mediterranean \\
\hline & IPHC & International Pacific Halibut Commission \\
\hline & Joint Commission & Joint Norwegian-Russian Fisheries Commission \\
\hline & NAFO & Northwest Atlantic Fisheries Organization \\
\hline & NASCO & North Atlantic Salmon Conservation Organization \\
\hline & NEAFC & North-East Atlantic Fisheries Commission \\
\hline & NPAFC & North Pacific Anadromous Fish Commission \\
\hline & NPFC ${ }^{b}$ & North Pacific Fisheries Commission \\
\hline & PSC & Pacific Salmon Commission \\
\hline & RECOFI & Regional Commission for Fisheries \\
\hline & SEAFO & South East Atlantic Fisheries Organization \\
\hline & SIOFA & Southern Indian Ocean Fisheries Agreement \\
\hline & SPRFMO & South Pacific Regional Fisheries Management Organization \\
\hline \multirow{20}{*}{$\begin{array}{l}\text { Advisory RFBs } \\
\text { Science }\end{array}$} & ICES & International Council for the Exploration of the Sea \\
\hline & PICES & North Pacific Marine Science Organization \\
\hline & SPC & Secretariat of the Pacific Community \\
\hline & APFIC & Asia-Pacific Fisheries Commission \\
\hline & BOBP-IGO & Bay of Bengal Programme Inter-Governmental Organization \\
\hline & CECAF & Fishery Committee for the Eastern Central Atlantic \\
\hline & COMHAFAT & Ministerial Conference on Fisheries Cooperation among African States Bordering the Atlantic Ocean \\
\hline & COREP & Regional Fisheries Committee for the Gulf of Guinea \\
\hline & CPPS & Permanent Commission for the South Pacific \\
\hline & CRFM & Caribbean Regional Fisheries Mechanism \\
\hline & FCWC & Fishery Committee of the West Central Gulf of Guinea \\
\hline & FFA & Pacific Islands Forum Fisheries Agency \\
\hline & NAMMCO & North Atlantic Marine Mammal Commission \\
\hline & OLDEPESCA & Latin American Organization for Fisheries Development \\
\hline & OSPESCA & Central America Fisheries and Aquaculture Organization \\
\hline & PERSGA $^{\mathrm{C}}$ & Regional Organization for the Conservation of the Environment of the Red Sea and Gulf of Aden \\
\hline & SEAFDEC & Southeast Asian Fisheries Development Center \\
\hline & SRFC & Subregional Fisheries Commission \\
\hline & SWIOFC & Southwest Indian Ocean Fisheries Commission \\
\hline & WECAFC & Western Central Atlantic Fishery Commission \\
\hline
\end{tabular}

a This list was developed for the purpose the UNEP Regional Oceans Governance Report [36] on the basis of FAO's RFB (list as at 2 July 2014).

b To be established.

c Once the Memorandum of Agreement for Regional Cooperation in Management of Fisheries and Aquaculture in the Red Sea and Gulf of Aden is adopted.

their diverging mandates, which can, inter alia, be specified geographically, in terms of species, in terms of functions (advisory or not) or a combination of these. The most important distinction is between RFBs with a management mandate that includes the competence to establish legally binding conservation and management measures - so-called regional fisheries management organisations (RFMOs) - and advisory RFBs. There are currently 41 marine RFBs worldwide, 21 of which are RFMOs and 20 advisory RFBs (three scientific and 17 management advisory) (Table 2).

The substantive mandates and objectives of RFBs depend first of all on the type they belong to. Moreover, significant differences exist between the objectives of some of the older RFBs, which are exclusively aimed at the sustainable utilisation and conservation of target species, and the newer RFBs, which pursue an ecosystem approach to fisheries (EAF), as introduced by the FAO in $2003^{7}$ [17].

(footnote continued)

Whaling Commission (IWC) and the Agreement on the Conservation of Albatrosses and Petrels (ACAP).

${ }^{7}$ An example of a new RFB that pursues an EAF is the South Pacific Regional Fisheries Management Organization (SPRFMO), whose objective is laid down in Article 2 of the 2009 Convention on the Conservation and Management of High Seas Fishery Resources in the South Pacific Ocean (SPRFMO Convention), which reads "The objective of this Convention is, through the application of the precautionary approach and an ecosystem approach to fisheries management, to ensure
Geographically, considerable differences also exist in the mandates of RFBs, depending on whether they cover both high seas and coastal State maritime zones, only or mainly high seas, or only coastal State maritime zones. With some exceptions, participation in the first two categories includes in general a mix of coastal States and high seas fishing States, whereas participation in the latter one is limited to coastal States.

Finally, global fisheries instruments often have a framework character and usually do not contain concrete fisheries conservation and management measures. Such measures (e.g. restrictions on catch and effort, minimum size limits for target species, maximum bycatch limits, gear specifications, temporal/seasonal or spatial closures) are commonly laid down in (sub) regional or bilateral fisheries instruments or in the decisions adopted by their bodies. These are often complemented by measures aimed at ensuring compliance, for instance boarding and inspection or port State measures [18].

(footnote continued)

the long-term conservation and sustainable use of fishery resources and, in so doing, to safeguard the marine ecosystems in which these resources occur". 
Table 3

Key features of regional oceans governance mechanisms.

\begin{tabular}{|c|c|c|c|}
\hline & Regional Seas programmes & RFBs & LME mechanisms \\
\hline $\begin{array}{l}\text { Geographical } \\
\text { scope }\end{array}$ & $\begin{array}{l}\text { Mostly coastal areas up to the outer limits of exclusive } \\
\text { economic zones (EEZs) - with the Antarctic, Medi- } \\
\text { terranean, North-East Atlantic and South Pacific re- } \\
\text { gional systems also covering areas beyond national } \\
\text { jurisdictions (ABNJ). }\end{array}$ & $\begin{array}{l}\text { Three groups: (1) both high seas and coastal } \\
\text { State maritime zones; ( } 2 \text { ) only or mainly the } \\
\text { high seas; and ( } 3 \text { ) only coastal State maritime } \\
\text { zones. }\end{array}$ & $\begin{array}{l}\text { Some in high seas but most in EEZ and } \\
\text { territorial sea only. }\end{array}$ \\
\hline Mandate & $\begin{array}{l}\text { From marine pollution to protection of marine } \\
\text { biodiversity } \\
\text { No mandate on what is covered by sectoral organisa- } \\
\text { tions such as the International Maritime Organisation } \\
\text { (IMO), the International Seabed Authority (ISA) and } \\
\text { FAO/RFBs. }\end{array}$ & $\begin{array}{l}\text { Advisory or not } \\
\text { Specific (types of) species or "residual" spe- } \\
\text { cies within a certain area; } \\
\text { Mostly only one human activity, namely } \\
\text { fishing (and associated activities); sometimes } \\
\text { also aquaculture and/or research; } \\
\text { Aimed at target species or EAF. }\end{array}$ & $\begin{array}{l}\text { Multi-sectoral ecosystem-based as- } \\
\text { sessment and management of LME } \\
\text { goods and services. }\end{array}$ \\
\hline Participation & $\begin{array}{l}\text { Only coastal States (with the exception of the Antarctic } \\
\text { Treaty System). }\end{array}$ & $\begin{array}{l}\text { Depending on spatial scope, either exclusively } \\
\text { coastal States or both coastal States and extra- } \\
\text { regional States (mostly distant water fishing } \\
\text { States). }\end{array}$ & Only coastal States. \\
\hline $\begin{array}{l}\text { Institutional } \\
\text { arrangements }\end{array}$ & $\begin{array}{l}\text { Secretariat/RCU, COP/inter-governmental meeting } \\
\text { RACs in some } \\
\text { Status depending on nature of relationship to UNEP. }\end{array}$ & $\begin{array}{l}\text { Stand-alone bodies or FAO bodies. } \\
\text { International organisations (with secretariat) or } \\
\text { COPs/MOPs (commonly without secretariat). }\end{array}$ & $\begin{array}{l}\text { Multi-agency partnership, under the } \\
\text { leadership of an international } \\
\text { organisation; } \\
\text { Very few institutions established (Ben- } \\
\text { guela Current Commission; Guinea } \\
\text { Current Commission probably soon) }\end{array}$ \\
\hline
\end{tabular}

a However, many Regional Seas programmes have adopted Oil spills/emergency protocols, which are also a topic in the framework of IMO's mandate. In some cases, RACs have been created to deal with this issue and are run or supported by IMO.

Table 4

Summary of avenues for progress and expected outcomes towards EBM.

\begin{tabular}{|c|c|c|}
\hline & Coherence outcomes & Effectiveness outcomes \\
\hline Revise the mandates of key players & Improve synergies and complementarities. & $\begin{array}{l}\text { Fill regional gaps and gaps on emerging issues; } \\
\text { Facilitate the implementation of the ecosystem approach to } \\
\text { fisheries. }\end{array}$ \\
\hline Strengthen individual mechanisms & $\begin{array}{l}\text { Provide enabling conditions for revised mandates } \\
\text { to be implemented. }\end{array}$ & $\begin{array}{l}\text { Provide means, especially financial, for Regional Seas programmes, } \\
\text { RFBs and LME mechanisms to deliver change. }\end{array}$ \\
\hline $\begin{array}{l}\text { Promote informal cooperation and co- } \\
\text { ordination arrangements }\end{array}$ & Improve synergies and complementarities. & $\begin{array}{l}\text { Increase overall effectiveness while avoiding thorny institutional } \\
\text { negotiations on formal reorganisations. }\end{array}$ \\
\hline Find a niche for LME mechanisms & $\begin{array}{l}\text { Solve the governance issue around LME } \\
\text { mechanisms. } \\
\text { Enhance clarity and readability of regional } \\
\text { oceans governance. } \\
\text { Avoid institutional proliferation. }\end{array}$ & $\begin{array}{l}\text { Make better use of the scientific basis provided by LME } \\
\text { mechanisms. }\end{array}$ \\
\hline
\end{tabular}

\subsection{LME mechanisms}

Based on a concept developed by the United States National Oceanic and Atmospheric Administration (NOAA), 66 LMEs have been identified. ${ }^{8}$ They are relatively vast areas of oceans of approximately $200,000 \mathrm{~km}^{2}$ or greater, adjacent to the continents in coastal waters where primary productivity is generally higher than in open ocean areas. The physical extent of an LME and its boundaries are based on four linked ecological, rather than political or economic, criteria9 ${ }^{9}$ : (i) bathymetry, (ii) hydrography, (iii) productivity, and (iv) trophic relationships.

LME mechanisms aim at implementing the ecosystem approach to the marine and coastal environment, from knowledge to management of human activities (such as fisheries, logging, mining, oil and gas exploitation, urban sprawl) and their impacts (such as marine and land-based sources of pollution). Besides some utilisation by the United States government itself for its 10 LMEs, since 1995 the GEF has been instrumental in promoting the

\footnotetext{
${ }^{8}$ See: 〈http://www.cbd.int/ecosystems/newsletters/ea-2009-10.htm〉.

9 See: $\langle$ http://lme.edc.uri.edu/index.php?option = com_content\&view = article\&id $=47 \&$ Itemid $=28\rangle$.
}

LME concept. Whereas the GEF is usually the financial mechanism for the implementation of a global convention (e.g. the United Nations Framework Convention on Climate Change (UNFCCC) or the $\mathrm{CBD}$ ), the marine and coastal sub-component of its International Waters (IW) focal area is based on the LME concept - a sui generis approach. As of 2013, the total GEF funding for 21 LME projects involving 110 countries amounted to USD 3.1 billion [19].

The GEF Operational Strategy invites "nations sharing an LME [to] begin to address coastal and marine issues by jointly undertaking strategic processes for analysing science-based information on transboundary concerns, their root causes, and by setting priorities for action on transboundary concerns. This process is referred to as a Transboundary Diagnostic Analysis (TDA). (...) Countries then determine the national and regional policy, legal, and institutional reforms and investments needed to address the priorities, and based on the strategies prepare and initiate an LME wide Strategic Action Program (SAP). This allows sound science to assist policy making within a specific geographic location for an ecosystem-based approach to management that can be used to engage stakeholders" [20]. Thirty-six TDAs and 30 SAPs had already been completed as of 2013 [19].

An important feature of the LME approach is the 5-module strategy for measuring the changing status of the ecosystem and 
for taking remedial actions towards recovery of degraded conditions [20]. The 5 modules are focused on the application of suites of indicators measuring (1) productivity, (2) fish and fisheries, (3) pollution and ecosystem health, (4) socio-economics, and (5) governance. The latter 2 are sometimes qualified as "the human dimensions" of LMEs [21] - and clearly the ones having received the least attention.

Beyond the GEF project cycle, three types of approaches have been tested to govern LMEs:

- Creation of a specific governance mechanism, as is the case of the Benguela Current LME with the signature of a Convention in 2013 which establishes the Benguela Current Commission (BCC) as a permanent inter-governmental organisation, to which Angola, Namibia and South Africa are members;

- Establishment of an LME Commission in the framework of an existing body: this is the case of the Guinea Current Commission (GCC) which is intended to be established by a dedicated protocol under the Abidjan Convention. ${ }^{10}$

- Cooperative governance, e.g. in the Mediterranean where existing international organisations (UNEP, the World Bank) are given the responsibility to implement the two SAPs (SAP-BIO and SAP-MED) in partnership with regional bodies (Mediterranean Action Plan (MAP), General Fisheries Commission for the Mediterranean (GFCM)) [22].

Table 3 synthetises the key features of the three types of regional oceans governance mechanisms described above.

\section{Successes and challenges of regional oceans governance mechanisms}

\subsection{Regional Seas programmes: well-established but struggling to deliver}

Regional Seas programmes are now well established in the oceans governance landscape. As noted by Ehler [23] in his global review, "the RSP, its conventions and protocols, and action plans have provided a forum for equitable participation by Member States in management processes of major seas of the world. It has promoted the idea of a "shared sea," and has helped place marine and coastal management issues on the political agenda and supported the adoption of environmental laws and regulations. For some Member States in some regions, the RSP is the only entry point for environmental concerns. It has encouraged and provided assistance for capacity building for marine and coastal management". The author further remarks that "substantial progress has been made over the past 30 years in addressing the problems of the world's oceans through the Regional Seas Programme and other global agreements and activities. There is convincing evidence that better management in some areas has cleaned up beaches and bathing waters and made seafood safer to eat". It is, however, difficult to precisely attribute observed progress in environmental conditions to a particular endeavour such as the RSP. Moreover, "although many Regional Seas programmes have made a positive difference, many have failed to solve the problems they were designed to solve" [23].

Several factors currently limit the effectiveness of Regional Seas programmes in tackling marine and coastal challenges. First, the implementation of regional agreements is far from systematic and comprehensive. The most glaring example is the disconnection

\footnotetext{
${ }^{10}$ In 2012, Parties to the Interim Guinea Current Commission agreed to establish a Permanent Commission by a Protocol to the Abidjan Convention.
}

between the number of regional agreements aimed at preventing land-based pollution and the persistence, and even worsening, of the problem. Many reasons, often cumulative, can explain this situation, including the lack of political will, political instability in some States or weak enforcement mechanisms [24]. The First Inter-Regional Programme Consultation ${ }^{11}$ identified "the lack of necessary interaction with the fisheries sector and other socioeconomic sectors" as one of the "most fundamental problems hampering the implementation of the respective Regional Seas programmes" [25].

Although it is difficult to draw a general picture, it is clear that many Regional Seas programmes are facing important financial shortfalls. For instance, the Coordinating Body on the Seas of East Asia (COBSEA)'s "financial situation continues to be critical: the core expenditures of the Secretariat are larger than that of the annual income from countries contributions to the Trust Fund and UNEP, as an interim emergency measure, pays for the difference". ${ }^{12}$ Similarly difficult financial situations are met e.g. in the Mediterranean, Caribbean and Western Indian Ocean regional systems.

Furthermore, despite the adoption of several action plans and legal agreements, many Regional Seas programmes still have the same institutional framework as when they were created, with limited financial and human resources [24]. Consequently, the necessary coordination, assistance and support to States in implementing the regional commitments and agreements are hardly provided by the secretariats, which are almost fully caught up in administrative issues. This hampers crucial, higher level strategic and political work as well as the provision of technical and legal assistance.

\subsection{RFBs: expanding coverage, growing challenges}

RFBs have become the primary vehicle for the conservation and management of transboundary and discrete high seas fish stocks. As regards straddling and highly migratory fish stocks, this was confirmed by article 8(1) of the 1995 United Nations Fish Stocks Agreement (FSA). Acknowledgement of the key role of RFBs is reflected in the efforts of the international community since the entry into force of the FSA to establish new RFMOs towards ensuring full coverage of the high seas. The most recent negotiations to establish RFMOs related to the South Pacific - which led to establishment of the South Pacific Regional Fisheries Management Organisation (SPRFMO) - and the North Pacific - which is expected to lead to the establishment of the North Pacific Fisheries Commission (NPFC) in the near future. Other successes of RFBs are the pro-active efforts of many RFBs to address the impacts of bottom-fisheries on the marine environment and to more broadly consider impacts of fisheries on ecosystems as a whole - rather than just target species - and to formally embrace the EAF by adjusting their institutive instruments.

However, RFBs face a considerable number of challenges, including:

- Gaps in full high seas coverage with RFMOs, among others in the Central and South-West Atlantic. Some regions also lack RFBs with a mandate over joint stocks, for instance in the Red Sea and the Gulf of Aden [26].

- Over-exploitation of target species and implementing a precautionary approach to fisheries management, among other

\footnotetext{
11 The Hague, 24-26 June 1998.

12 Twenty-first Meeting of the Coordinating Body on the Seas of East Asia (COBSEA), Report of the UNEP Executive Director on the implementation of the East Asian Seas Action Plan 2009-2012, Bangkok, Thailand, 26 March 2013, UNEP/DEPI/ COBSEA IGM 21/3, Section 8:8.
} 
things due to overcapacity and subsidies.

- Allocating fishing opportunities and the so-called "conservation burden" [27].

- Illegal, unreported and unregulated (IUU) fishing - including dealing with new entrants - monitoring, control and surveillance and ensuring compliance.

- Scientific research, data gathering and data sharing on target species and on what is necessary to pursue EAF.

- Delay in closing areas of the high seas to bottom fishing activities where there is likely to be significant adverse impacts to vulnerable marine ecosystems (VMEs), as requested by Resolution 61/105 (2006) of the United Nations General Assembly [28].

- Implementing EAF, among other things in relation to by-catch of non-target species (fish and non-fish; e.g. large-scale pelagic drift-nets); discarding of target and non-target species; impacts on benthic habitats; other unsustainable fishing practises (e.g. dynamite and cyanide fishing); and lost and discarded fishing gear and packaging material (ghostfishing).

- Limited budgets of RFB secretariats, where relevant.

- Management and/or advisory mandates of RFBs are inherently limited and do not allow them to regulate with other human activities impacting on fisheries (e.g. coastal zone development, marine pollution (including marine debris) and global climate change) or even with some fisheries issues (e.g. subsidies).

As the performance of RFBs has suffered and continues to suffer from all these challenges, various processes - including RFB performance assessments and revisions of the constitutive instruments of RFBs - have been and are undertaken to address them [29].

\subsection{LME mechanisms: Project-based successes now facing the gov- ernance challenge}

As Mahon et al. [30] note, "the LME concept (...) has had a global impact on how projects to address (...) problems are developed and funded. (...) The LME concept has provided a rallying point for countries to cooperate in dealing with problems relating to the utilisation of transboundary resources". LME mechanisms indeed have been instrumental in strengthening regional oceans governance in several ways. First, they have generated significant advances in the scientific knowledge of the marine environment, its resources and biodiversity, and a wealth of useable scientific information [31]. This has been the basis for the development of robust, comprehensive and accessible assessments through TDAs. Second, they have invested a lot of resources in capacity building. For instance, no less than 80 capacity building workshops were organised within the framework of the Guinea Current Large Marine Ecosystem (GCLME) project [32]. Last, although sometimes competing with other regional bodies to find their "ecological niche", LME mechanisms also stimulated regional cooperation to some extent, bringing together regional stakeholders for various meetings and occasioning discussions that would otherwise not have taken place. This may include RFBs and Regional Seas programmes, but also non-governmental actors.

On the other hand, LME mechanisms today face a number of crucial challenges. The modules approach generates a first range of problems. As Mahon et al. [30] note, there remains a "lack of clarity as to exactly what is contained in the modules. They appear to be mixed and have fuzzy boundaries". Moreover, "the compartmentalisation in the LME approach implies that the science activities, especially the productivity module, stand alone from governance, rather than in support of it". Last, "it perpetrates the perception that governance cannot take place without first carrying out a great deal of scientific research". In this regard,
Bensted-Smith and Kirkman [31] underline that "most GEF LME projects invest predominantly in applied research, feasibility assessments, plans and management recommendations, and in training". Funding for more concrete, game-changing activities leading to changes in actual practises has been scarcer, which is a constraint, especially in least developed countries where governance is weak and domestic sources of funding meagre. As of today, multiple phases of GEF funding are usually needed.

Second, while LME "supporters" (especially the GEF Secretariat and NOAA) claim that the projects are country driven [20], they are still being criticised for a top-down approach in which neither States nor regional bodies really have a say. Their scientific basis and hence the design of their boundaries have been developed by NOAA's scientists, while the funding of LME projects by the GEF under its IW focal area follows a somewhat mechanical approach: the formal and procedural requirements, such as official endorsement by recipient countries, do not guarantee that national demand and ownership receive the attention and weight they deserve.

Third, the issue of financial sustainability of the LME approach needs to be raised. Duda and Sherman [33] promote the periodic updating of TDAs and SAPs, and Sherman and Hempel [20] affirm that "from year 1, the GEF supported projects move toward the goal of self-financing of the ecosystem assessment and management process by year 10 ". What happens in practise once a LME project ends remains an open question. While there is a tendency to follow up with second or third phases, the very nature of the GEF means that successive funding phases cannot be a general answer to the sustainability issue. The risk of TDAs becoming obsolete after the completion of the GEF project is hence real. The necessary updating process of knowledge and analysis cannot be ensured in a systematic way if no governance mechanism is clearly in charge.

A fourth challenge is therefore to identify who may take over once the TDA and SAP have been produced and the project terminated. Some issues addressed by TDAs and SAPs are handled by existing regional bodies whose mandates are fragmented and whose geographical scopes do not necessarily fit with LME delimitations. Therefore, there may be a temptation to create new regional bodies ex nihilo, with an integrated mandate which allows them to implement the ecosystem approach. The creation of the Benguela Current Commission shows that it is possible - but its funding by members will need to be scrutinised. In any case, the governance issue is fundamental because of the progressive shift from an essentially scientific approach primarily guided by NOAA's own needs, towards what is nowadays closer to an investment guide for a variety of international and national agencies [31]. The situation is therefore radically different from that of Regional Seas programmes, where implementation of agreed action plans and work programmes is coordinated and monitored by an existing, designated secretariat or coordinating unit.

On the whole, LME mechanisms offer a robust scientific basis for action but face a critical governance challenge.

\subsection{Conclusion}

Regional oceans governance mechanisms are sectoral by construction. This is clearly the case for RFBs (fisheries), but also for Regional Seas programmes which, however multi-sectoral in principle, do not have a regulatory mandate over key economic sectors such as fisheries, offshore exploitation of non-living marine resources and shipping. While LME mechanisms aim to be cross-sectoral, in reality this is hardly the case either because they are not yet operational from a governance point of view, or due to existing competent international bodies at the global or regional level. In this context, the implementation of EBM is challenging 
and, in particular, cumulative impacts are usually not taken into account in management decisions.

Whatever the level of support that regional mechanisms may provide, it is worth underlining that implementation is largely in the hands of States. However, a number of them, especially in the developing world, still face structural difficulties. In many cases, public administrations, be they national or local, do not have the capacity nor the means to design and implement strong environmental policies, which clearly hampers the effectiveness of regional governance. Where States and administrations are relatively stronger, lack of coordination and even conflicting objectives between sectoral policies are common obstacles to the implementation of MEAs.

\section{Cooperation and coordination among and between regional oceans governance mechanisms}

\subsection{Cooperation and coordination among regional oceans govern- ance mechanisms}

\subsubsection{Among Regional Seas programmes}

There are several formal and informal mechanisms aimed at ensuring cooperation and coordination among Regional Seas programmes. First, the RSP is the designated UNEP programme which provides a framework for coordination and institutional support to individual Regional Seas programmes. It provides programmatic support and assistance in the implementation of the conventions and action plans of the UNEP-administered Regional Seas programmes. Moreover, global meetings of Regional Seas programmes are regularly organised, giving the opportunity to share regional experiences and adopt Global Strategic Directions ${ }^{13}$. Some formal agreements have also been concluded between Regional Seas programmes in order to collaborate on specific issues: that is the case, for instance, for the North-East Atlantic and West, Central and Southern African regions, and for the North-East Atlantic and the Baltic regions, which established Memoranda of Understanding (MoUs). Coordination and cooperation can also focus on specific issues, for instance the joint action on ballast water exchange by the OSPAR Commission, Helsinki Commission and the parties to the Barcelona Convention. ${ }^{14}$ Last and more informally, experiences between Regional Seas programmes are sometimes exchanged through the participation of staff members from one programme in meetings of another programme.

\subsubsection{Among RFBs}

Coordination and cooperation among RFBs is stimulated and encouraged by FAO, for instance through the Regional Fishery Body Secretariats Network (RSN) that it has been hosting since 2007 and the Meetings of RFBs that it convened between 1999 and $2005 .^{15}$ Examples of regular meetings between RFBs are the socalled "Kobe process ${ }^{16}$ " involving the five tuna RFMOs. It is also common for RFBs to formalize cooperation with other RFBs by means of MoUs, to have standing agenda-items on such cooperation, to accord each other observer status and to send designated representatives to each other's meetings. Finally, cooperation and

\footnotetext{
${ }^{13}$ The global strategic directions for the Regional Seas programmes for 20132016 are listed at 〈www.unep.org/regionalseas/about/strategy/default.asp〉.

14 Joint Notice to Shipping from the Contracting Parties of the Barcelona Convention, OSPAR and HELCOM on General Guidance on the Voluntary Interim Application of the D1 Ballast Water Exchange Standard by Vessels Operating between the Mediterranean Sea and the North-East Atlantic and/or the Baltic Sea (Annex 17 to 2012 OSPAR Summary Record).

${ }^{15}$ For information see 〈www,fao.org/fishery/topic/16820/en〉.

${ }^{16}$ For information see $\langle$ tuna-org.org $\rangle$
}

coordination can also focus on specific issues, such as shared stocks and fisheries in areas where two conventions/regulatory areas overlap. ${ }^{17}$

\subsubsection{Among LME mechanisms}

Cooperation, exchange of information and dissemination of good practises among LMEs are processed through four types of mechanisms. First is the annual Consultative Meeting on LMEs jointly organised by IOC-UNESCO, IUCN and NOAA, which provides an opportunity to address issues of common interest for LME mechanisms. 15 such meetings have already taken place. Second are the bi-annual IW Conferences organised by the GEF Secretariat which are opportunities to present the state of implementation and results of GEF projects related to IW, including - but not limited to - LME projects. Third is the GEF IW: LEARN website ${ }^{18}$, a platform which allows for exchanging, learning and providing resources between GEF IW projects, including LMEs. Fourth are ad hoc regional initiatives: in the North-East Atlantic, North Sea, Arctic and Baltic Sea, an ICES initiative on LME cooperation is carried out through the Working Group on Large Marine Ecosystems Best Practices which operates under the Scientific Committee Steering Group on Regional Seas programmes; in Africa the African LME caucus encourages collaboration and synergies between African LMEs and publishes a newsletter to exchange information and experiences.

\subsection{Cooperation and coordination between regional oceans gov- ernance mechanisms}

\subsubsection{Between Regional Seas programmes and RFBs}

Cooperation and coordination between Regional Seas programmes and RFBs "reflects the growing nexus between fisheries and environmental management (...). Underpinning this relation are the concepts and obligations of (...) international instruments which apply to both" [25]. This cooperation is an already longstanding concern as evidenced by its consideration at the 2000 UN Subcommittee on Ocean and Coastal Areas and the 2001 joint UNEP-FAO initiative. The latter led to a substantial report which provides various options to enhance cooperation and coordination between Regional Seas programmes and RFBs [25].

Several Regional Seas programmes and RFBs have formalized their cooperation by means of MoUs (e.g. the Regional Seas programme for the Western Indian Ocean and the Southwest Indian Ocean Fisheries Commission (SWIOFC); the UNEP MAP and the GFCM), have standing agenda-items on cooperation, accord each other observer status and send designated representatives to each other's meetings. Finally, reference can also be made to the on-going cooperation and coordination between the various components of the Antarctic Treaty System, in particular the Antarctic Treaty Consultative Meetings, the Committee on Environmental Protection and CCAMLR.

\subsubsection{Between Regional Seas programmes and LME mechanisms}

Cooperation and coordination between Regional Seas programmes and LME mechanisms is stimulated and encouraged by UNEP, one of the GEF implementing agencies, for instance by means of its Global Strategic Directions for Regional Seas programmes. $^{19}$

Formally, the GEF is not a financial instrument for the implementation of marine conventions. This is made very clear in the GEF fourth evaluation report: "Because the GEF does not follow

\footnotetext{
${ }^{17}$ E.g. between CCAMLR and CCSBT in relation to fishing for southern bluefin tuna in the CCAMLR Convention Area; between IATTC and WCPCF on tuna fisheries in the WCPFC/IATTC Overlap Area.

18 See: 〈www.iwlearn.net〉.

${ }^{19}$ Listed under no. 3 at (www.unep.org/regionalseas/about/strategy/default.
} 
guidance from conventions in IW, it has developed the focal area full strategy itself. In the other GEF focal areas, the main aim is to support countries in implementing the obligations of the conventions in national policies and strategies. [...] In IW, the important first steps in the overall strategy are the TDA and SAP to create a basis for international cooperation, hopefully leading to binding agreements among governments to deal with urgent problems in the transboundary water systems they share" [34]. Existing binding agreements, especially Regional Seas conventions and their protocols, are not mentioned here.

However, Sherman and Hempel [20] mention the "partnership (...) that links the global Regional Seas Programme, coordinated by UNEP, with the Large Marine Ecosystem approach" (...); "the joint initiative assists developing countries in using LMEs as operational units for translating the Regional Seas Programme into concrete actions". Therefore, in spite of some temptation at the beginning of the implementation of the IW component, there is no tabula rasa policy. GEF-funded LME projects have to cope with the legal and political reality in countries involved, which can be Contracting Parties to an existing regional marine convention (e.g. the Barcelona Convention in the Mediterranean or the Abidjan Convention in West, Central and Southern Africa), or to an action plan with no legally binding instrument (e.g. COBSEA). It takes different forms, from an integrated approach in the Mediterranean case to a cooperative approach in the GCLME case where, in spite of the establishment of a separate secretariat, the GCLME project was instrumental in strengthening the Abidjan Convention through the adoption of a Land-based pollution Protocol and an Emergency Protocol to the Convention. Examples of more uncertain cooperation and coordination between Regional Seas programmes and LME mechanisms include the (permanent but autonomous) BCC, which is supposed to cooperate with relevant organisations including both Regional Seas programmes and RFBs. ${ }^{20}$

\subsubsection{Cooperation and coordination between RFBs and LME mechanisms}

Interactions between RFBs and LME mechanisms are necessarily more limited than between Regional Seas programmes and LME mechanisms for at least two reasons. A legal one, first: LMEs as delimited under NOAA guidance mainly consist of coastal States maritime zones. On the other hand, while some RFBs have geographical mandates covering coastal State maritime zones, the mandates of most non-tuna RFMOs cover only or mainly high seas. A substantive reason, then: with most LME mechanisms being driven primarily by environmental concerns, RFBs and national fisheries authorities have not always been actively involved in LME discussions and decisions, despite marine capture fisheries often being among the main concerns.

On the whole, LME mechanisms have mainly been oriented towards sui generis initiatives such as the BCC whose mandate covers fisheries. Nevertheless there has been some limited but tangible cooperation between LME mechanisms and RFBs, such as:

- Involving RFBs as partners in the coordinating process of LME projects: for instance, the Baltic Sea Fishery Commission (no longer operational) was involved in the Baltic Sea Regional GEF LME Project, and the GFCM in the GEF Mediterranean LME project/

- Supporting RFBs' projects [35]. For instance, the GEF South China Sea LME Project was instrumental in the decision by the Southeast Asian Fisheries Development Center (SEAFDEC) to establish regional fisheries refugia for transboundary fisheries management. In the Pacific, after the establishment of the

\footnotetext{
${ }^{20}$ Cf. Art. 18 of the Benguela Current Convention.
}

Western and Central Pacific Fisheries Commission (WCPFC), ${ }^{21}$ the GEF funded the Pacific Islands Oceanic Fisheries Management Project which aimed at strengthening the capacity of small islands to implement fisheries management rules, especially those of the WCPFC. This project fits with GEF's role as the financial instrument of the Rio conventions: it helps developing countries to comply with their international obligations in terms of environmental protection and the sustainable use of living resources. The same applies e.g. to the West Pacific East Asia Oceanic Fisheries Management Project.

In addition, FAO is currently (co)implementing two LME projects (Bay of Bengal and Canary Current) and is or has been involved in different capacities in other LME projects.

\subsection{Conclusion}

Experiences show that the level of cooperation and coordination between regional oceans governance mechanisms widely varies from one region to another.

The east Asian region Is a telling example of organisational complexity and lack of coordination between regional oceans governance mechanisms [36]. the two regional Seas programmes (i.e. COBSEA and the Northwest pacific action plan (NOWPAP)) and two RFBs (the Southeast Asian Fisheries development center (SEAFDEC) and the Asia-pacific fishery Commission (APFIC)) are complemented by $5 \mathrm{LMEs}^{22}$, some of them still being purely ecological concepts, while others have been the subject of a GEF LME project. to make it more complex, some GEF projects covered two LMEs, with one not part of the region in the Partnerships in environmental management for the Seas of east Asia (PEMSEA) sense (like the south China SEA and gulf of Thailand LME projects), while PEMSEA was originally a GEF coastal management project and not an LME project, and eventually became an additional international organisation. the potential yellow SEA Commission, emerging from the yellow SEA LME project with NOWPAP and RFBs preexisting, Is another example of questionable addition of layers of institutions.

Conversely, in the Western, Central and Southern Africa, the cooperation between RFBs and the Abidjan Convention seems to be on track, as demonstrated by the 2012 Decision by the Contracting Parties to the Abidjan Convention to work together with these organisations and develop fields of cooperation ${ }^{23}$ : competent organisations must now make this cooperation effective through formal mechanisms and joint activities, especially by creating linkages between fisheries management and biodiversity conservation. The ecosystem approach, as promoted by LME mechanisms, is widely recognised and taken into account by RFBs and the Abidjan Convention. The GCLME has proven useful in the process of revitalising the Abidjan Convention, especially in the field of oil spill response, land-based pollution and mangroves conservation. The CCLME currently implemented has also established collaborations both with the Abidjan Convention and the Sub Regional Fisheries Commission (SRFC). The decision to create the GCC within the Abidjan Convention framework through a protocol to the convention is a positive approach in terms of

\footnotetext{
${ }^{21}$ The establishment of the WCPFC is presented by GEF IW-Learn website as a result of the GEF IW programme ("GEF interventions are often associated with adopting regional conventions as a show of the government commitments to sustainability after the project ends. For example, the WCPFC resulted from GEF-IW waters"). In fact, the decision to launch the negotiation for the establishment of the WCPFC was taken in 1994, before the adoption of the IW component by the GEF.

${ }^{22}$ South China Sea, Sulu-Celebes Sea, Indonesia Sea, East China Sea and Yellow Sea

${ }^{23}$ Decision CP.10/15.
} 
governance and will certainly facilitate the creation of synergies between both mechanisms. Last, modalities of cooperation between the Abidjan Convention and the BCC, created as an independent intergovernmental organisation, remain to be worked out.

The main challenge of cooperation and coordination lies in the fact that the three layers of governance investigated in this paper have been conceived and designed successively and independently from one another, not as a bundle of complementary tools - which they should eventually be. And as rightly identified by UNEP [25], "another potential constraint is the lack of any existing coordination and cooperation within countries between national sectors (ministries) dealing with fisheries and environmental protection. In some cases they jealously guard their "mandates" and they even act as adversaries rather than partners".

Complementarity indeed does not mean that interests and logics necessarily converge at all times on all matters. For instance RFBs may be more likely to optimise economic interests; or Regional Seas programmes may be mostly interested in protection of non-target species and benthic habitats; or RFBs may complain about the lack of attention and action from Regional Seas programmes on land-based sources of pollution, which negatively affect fisheries. The painful negotiations around the so-called Collective Arrangement promoted by OSPAR show that in practise such organisations often promote conflicting interests [37,38]. Here the absence of an obligation to cooperate and a clear framework to do so (beyond MoUs) is particularly problematic.

Last, when considering RFBs and Regional Seas programmes, we often talk about coordinating individually weak mechanisms: most are often short of resources to effectively implement their mandate, and States remain the key actors when it comes to concrete implementation of measures agreed at the regional level. Therefore, while cooperation and coordination are major requirements for EBM, they should never overshadow the basic need to strengthen each mechanism in itself in the first place. As an illustration, even if the mandate to lead the implementation of SAPs was to be systematically given to Regional Seas programmes, some would hardly have the means and capacity to do so effectively. EBM requires extensive cooperation and coordination among and between individually strong mechanisms.

\section{Conclusion: options towards more coherent and effective regional oceans governance}

In this section, attention is firstly given to strategic dead-ends that should be avoided in the future, before providing positive recommendations.

\subsection{Dead-end tracks}

Three key dead-end tracks should be avoided in the future.

First, bypassing existing regional oceans governance mechanisms with internationally funded projects is not a solution, even in cases where they are deemed weak and unable to deliver change. The last fifty years of international development cooperation show that bypassing inefficient administrations has been a constant temptation of a wide range of donors [39], but experience demonstrates that this does not lead to strong outcomes. Not only does it fail to strengthen governance mechanisms, but it also weakens those which are not supported, making them ever more difficult partners to work with.

Second, developing legal agreements or action plans without seriously considering future implementation issues, especially human and financial resources, should be avoided. This is true of all governance mechanisms including Regional Seas programmes
[16] and LME mechanisms, which have often adopted agreements and action plans without enough consideration for implementation requirements and governance coherence.

Last, passively or actively maintaining weak regional oceans governance mechanisms while claiming the importance of the regional approach to ocean governance leads to nowhere. Independently from, or rather in conjunction with, coordination efforts to avoid duplication and competition for scarce resources, individual mechanisms need to be strengthened in their capacity to execute their mandate and deliver change.

\subsection{The way forward}

\subsubsection{Revise the mandates of key players}

There is a need to progressively revise the mandates of various regional oceans governance mechanisms so as to improve synergies and complementarities in the international oceans governance regime as a whole. Depending on specific cases, this requires: (i) promoting residual mandates in case no other competent international body exists, along the lines of the OSPAR Commission, which would allow new and emerging issues to be addressed; (ii) broadening mandates of RFBs beyond the management of target species to facilitate EAF; (iii) broadening mandates of Regional Seas programmes to ensure ecosystem-based management, while taking account of the mandates of existing international bodies (including RFBs and relevant global bodies such as IMO and the International Seabed Authority; and (iv) filling gaps, e.g. in the coverage of ABNJ [12].

\subsubsection{Strengthen individual mechanisms}

First, the shortcomings of regional oceans governance mechanisms are no reason to ignore them, but rather to strengthen them. Second, broadening or revising the mandates of existing mechanisms as we suggest may actually be useful only if these mechanisms are strengthened at the same time; for instance, expanding the mandate of an underfunded and understaffed Regional Seas programme to $\mathrm{ABNJ}$ is pointless. Last, ensuring increased and sustainable funding for regional oceans governance mechanisms is crucial - though not sufficient. Given the reluctance or inability of many States to increase their direct contributions, other funding sources should be explored, especially among so-called "innovative financial mechanisms" [40] such as levies, payments for ecosystem services, user fees etc. The currently intense international activity on such topics should be a source of inspiration.

\subsubsection{Promote informal cooperation and coordination arrangements}

The complexity of regional oceans governance is grounded in history and regional contexts, and reflects the diversity of views, concerns and stakeholders in a pluralistic manner. It may thus only be simplified at its margins: the dream of having a simple governance system with single regional bodies managing the marine environment, its resources and its biodiversity, the human activities it supports, within boundaries that fit those of ecosystems may be a seductive utopian horizon but will not come true in the foreseeable future. Therefore, it may be recommended to develop informal mechanisms rather than strive for formal reorganisations.

For instance merging Regional Seas programmes and RFBs into so-called Regional Oceans Management Organisations (ROMOs) [41] is not a generally applicable option. While it may be the way forward in a few very specific cases, (i) geographical scopes and participation are too heterogeneous; (ii) national administrations in charge of fisheries management and protection of the marine environment are often separate with different constituencies and diverging logics (usually environmental protection vs. fisheries 
development); and (iii) inter-sectoral conflicts which are currently visible between fisheries management and environmental protection mechanisms would become less visible but would not necessarily be solved.

The case of the BCC, established in 2007, is interesting but should not be taken as a model because it arose from a specific context (with e.g. a very large Regional Seas programme). Its generalisation when regional mechanisms already exist would contribute to the institutional proliferation syndrome. In any case, besides the three types of regional oceans governance mechanisms that are examined in this article, there are plenty of other mechanisms, some including non-state actors, ranging from regional programmes such as the Programme Régional Côtier et Marin (PRCM) in West Africa, regional initiatives such as the Coral Triangle Initiative, regional environmental projects funded by a variety of donors besides the GEF, regional fisheries projects such as SWIOFP in the Indian Ocean, sub-regional agreements such as the Agreement on the Conservation of Cetaceans in the Black Sea, Mediterranean Sea and Contiguous Atlantic Area (ACCOBAMS), etc. These numerous and diverse other mechanisms usually have some forms of ad hoc working relations with one or several of the Regional Seas programmes, RFBs and/or LME mechanisms. However their large number and diversity preclude any serious attempt at systematisation. Trying to fully integrate the governance system formally rather than functionally is but a pipe dream.

\subsubsection{Find a niche for $L M E$ mechanisms}

LME mechanisms require specific attention. Many LMEs are only materialised by a GEF project. This raises concerns as to their sustainability, even when second or third phases are planned or underway. At the same time, an increasing number of originally GEF-supported LME projects give birth to formal and perennial organisations such as the BCC, the PEMSEA or the would-be GCC. While this answers the sustainability issue, it raises other concerns about the 'niche' they may occupy in the future. As Christie et al. [42] put it: "starting the boundary designation from a natural science perspective is questionable from a programme feasibility perspective unless governance institutions are to be redesigned along ecological principles - an unlikely outcome". Given that there is no significant sectoral gap in mandates of existing, formal mechanisms, any governance responsibility that may be given to, or claimed by, LME mechanisms, risks leading to more overlaps and inefficiencies. We concur with Bensted-Smith and Kirkman [31] that in general, GEF LME projects should invest in strengthening existing Regional Seas programmes and building links between other relevant regional institutions, rather than creating new inter-governmental commissions.

Whereas the added value of LME mechanisms with regard to TDAs and SAPs is acknowledged, there is also a widespread expert diagnosis that the governance dimension of LME mechanisms needs further consideration. The GEF, and probably NOAA as well given its key role, should develop and adopt an explicit and comprehensive strategy with regard to LME governance, in cooperation with important partners such as UNEP, FAO, the United Nations Development Programme (UNDP), UNESCO and IUCN. While outlining this strategy goes beyond the objectives of this paper, some guiding principles are suggested:

- Governance, and its knowledge needs, should be first and drive scientific assessments in an iterative process, rather than being perceived as a logical end-product of the assessment process.

- LME mechanisms may form a platform for scientific assessments, capacity building and on-the-ground interventions, but these should be operated under existing regional oceans governance frameworks wherever possible (e.g. Mediterranean).

- When a new international body is deemed necessary to implement the LME approach in a sub-geographic area of a Regional Seas programme, it may be established under the latter's framework, for instance as envisaged for the GCC under the Abidjan Convention.

- Although considered a flagship governance outcome of the LME approach, replication of the BCC scenario should be based on a detailed and context-specific governance gap analysis rather than being considered a generally applicable pathway. Such commissions need to build working-relationships with other regional oceans governance mechanisms.

- LME mechanisms should be used primarily as catalysers of change in existing regional oceans governance mechanisms, as has been the case in the Western, Central and Southern Africa region.

- To allow a clearer governance strategy to be developed, terms and concepts should be clarified. Confusion is noticeable on organisational matters in the LME literature, which is grounded in the governance weaknesses of the LME approach. For instance, Sherman and Hempel [20] mention the "partnership between UNEP and the LME approach", but how can an international organisation partner with "an" approach"? Another example is that cooperation and coordination between Regional Seas programmes, RFBs and LME mechanisms is reviewed here, but in parallel the IOC of UNESCO is investigating the complementarity of LMEs, integrated coastal management (ICM) and MPAs within the framework of a GEF project [43]. How can LMEs be ecosystems (by definition), organisations (comparable with Regional Seas programmes and RFBs), approaches (according to Sherman and Hempel [20]), management instruments (comparable to MPAs) and GEF projects at the same time? This adds some confusion to an already complex governance system. And this is not by accident but rather because the very nature of what LMEs are, what they are made for and how they relate to formal bodies and mechanisms, have remained unclear over the last 20 years.

Moving along those four avenues for progress (Table 4) would increase coherence in regional oceans governance by improving synergies and complementarities, enhancing overall clarity and readability, avoiding institutional proliferation and providing an enabling environment for revised mandates to be implemented. Regional oceans governance could also be more effective by filling regional gaps and gaps on emerging issues, facilitating EAF, providing (financial) means for Regional Seas programmes, RFBs and LME mechanisms to deliver change, avoiding thorny institutional negotiations on formal reorganisations and making better use of the scientific basis provided by LME mechanisms. These are practical and, presumably, efficient ways to progressively bring regional oceans governance closer to achieving EBM while enhancing accountability, preventing further complexity and strengthening the science-policy interface.

\section{Acknowledgements}

This article builds on a study commissioned to the authors by UNEP and referenced as: UNEP. Regional Oceans GovernanceMaking Regional Seas Programmes, Regional Fishery Bodies and Large Marine Ecosystem Mechanisms Work Better Together. UNEP Regional Seas Report and Studies no. 195; 2015 (in press). The authors would like to thank UNEP staff who provided guidance, information and insights. Special thanks go to Takehiro Nakamura. The views expressed in this publication are however those of the authors and do not imply endorsement by UNEP or any of the organisations the authors work with. 


\section{References}

[1] Halpern BS, Walbridge S, Selkoe KA, Kappel CV, Micheli F, D'Agrosa C, Bruno JF, Casey KS, Ebert C, Fox HE, Fujita R, Heinemann D, Lenihan HS, Madin EMP, Perry MT, Selig ER, Spalding M, Steneck R, Watson R. A global map of human impact on marine ecosystems. Science 2008;319(5865):948-52.

[2] Ramirez-Llodra E, Tyler PA, Baker MC, Bergstad OA, Clark MR, Escobar E, Levin LA, Menot L, Rowden AA, Smith Van Dover CRL. Man and the last great wilderness: human impact on the deep sea. PLOS ONE 2011.

[3] Rayfuse R. Research Handbook on International Marine Environmental Law. 2015 in press.

[4] Alheritiere D. Marine pollution control regulation: regional approaches. Mar Policy 1982:6:162-74

[5] Hayward P. Environnemental protection - regional approaches. Mar. Policy 1984:106-99.

[6] Vallega A. The regional scale of ocean management. Ocean Coast. Manag. 1998;39:179-88.

[7] Warner R, Gjerde K, Freestone D. Regional governance for fisheries and biodiversity. In: Garcia SM, Rice J, Charles A, editors. Governance of Marine Fisheries and Biodiversity Conservation: Interaction and Coevolution. United Kingdom: John Wiley and Sons; 2014. p. 211-24.

[8] Rochette J, Chabason L. L'approche régionale de préservation du milieu marin: l'expérience des mers régionales. In: Jacquet P, Pachauri R, Tubiana L, editors. A Planet for Life 2011. New Delhi: TERI Press; 2011. p. 111-21.

[9] Cicin-Sain B, Knecht R. Integrated Coastal and Ocean Management, Concepts and Practices. Washington, DC: Island Press; 1998.

[10] UNEP, Ecosystems and Biodiversity in Deep Waters and High Seas, UNEP/ IUCN, Switzerland, UNEP Regional Seas Reports and Studies no.178, 2006.

[11] UNEP, Achievements and planned development of UNEP's Regional Seas Programme and Comparable Programmes Sponsored by Other Bodies, UNEP Regional Seas Reports and Studies, no. 1, Nairobi, 1982.

[12] Rochette J, Unger S, Herr D, Johnson D, Nakamura T, Packeiser T, Proelss A, Visbeck M, Wright A, Cebrian D. The regional approach to the conservation and sustainable use of marine biodiversity in areas beyond national jurisdiction. Mar. Policy 2014;49:109-17.

[13] Vallega A. The regional approach to the ocean, the ocean regions, and ocean regionalization-a post-modern dilemma. Ocean Coast. Manag. 2002;45:721 60.

[14] J. Rochette, M. Wemaëre, R. Billé, G. du Puy-Montbrun, A contribution to the interpretation of legal aspects of the Protocol on Integrated Coastal Zone Management in the Mediterranean, UNEP, MAP, PAP/RAC, Split, 2012.

[15] Rochette J, Billé R. ICZM protocols to regional seas conventions: what? why? how? Mar. Policy 2012;36:977-84.

[16] J. Rochette, R. Billé, Strengthening the Western Indian Ocean Regional Seas Framework: A Review of Potential Modalities, IDDRI Studies no. 02, Paris 2012.

[17] FAO. The Ecosystem Approach to Fisheries, Issues, Terminology, Principles. Rome: FAO; 2003

[18] Molenaar EJ. Current and prospective roles of the Arctic Council system within the context of the Law of the Sea. Int. J. Mar. Coast. Law 2012;27:553-95.

[19] K. Sherman, "Introduction", IOC-IUCN-NOAA Large Marine Ecosystem, 15th Consultative Committee Meeting, Paris, France, 10 July 2013.

[20] K. Sherman, G. Hempel (Eds.), The UNEP Large Marine Ecosystem Report: A perspective on changing conditions in LMEs of the World's Regional Seas, UNEP Regional Seas Report and Studies no.182, Paris, France, Nairobi, 2008

[21] Sustaining large marine. In: Hennessey T, Sutinen J, editors. Ecosystems: The Human Dimension. Amsterdam: Elsevier; 2005.

[22] UNEP-MAP/GEF Strategic Partnership for the Mediterranean Sea Large Marine Ecosystem (MedPartnership), Inception Report, UNEP(DEPI)/MED WG.345/3, 21 May 2010.
[23] C. Ehler, A Global Strategic Review, Regional Seas Programme, United Nations Environment Programme, 2006.

[24] Rochette J, Billé R. Bridging the gap between legal and institutional developments within regional seas frameworks. Int. J. Mar. Coast. Law 2013;28 (3):433-63.

[25] UNEP, Ecosystem-based Management of Fisheries: Opportunities and Challenges for Coordination Between Marine Regional Fishery Bodies and Regional Seas Conventions, UNEP Regional Seas Reports and Studies no.175, Nairobi, 2001.

[26] Ban NC, Bax NJ, Gjerde KM, Devillers R, Dunn DC, Dunstan PK, Hobday AJ, Maxwell SM, Kaplan DM, Pressey RL, Ardron JA, Game ET, Halpin PN. Systematic conservation planning: a better recipe for managing the high seas for biodiversity conservation and sustainable use. Conserv. Lett. 2014;7:41-54.

[27] Hanich Q, Ota Y. Moving beyond rights-based management: a transparent approach to distributing the conservation burden and benefit in tuna fisheries. Int. J. Mar. Coast. Law 2013;28:135-70.

[28] G. Wright, J. Ardron, K. Gjerde, J. Rochette, Advancing marine biodiversity protection through regional fisheries management: a review of high seas bottom fisheries closures, IDDRI, Working Paper no. 14, Paris, 2014

[29] FOA. State of the World Fisheries and Aquaculture, Opportunities and Challenges. Rome: FAO; 2014.

[30] Mahon R, Fanning L, McConney P. A governance perspective on the large marine ecosystem approach. Mar. Policy 2009;33:317-21.

[31] Bensted-Smith R, Kirkman H. Comparison of Approaches to Management of Large Marine Areas. Cambridge, UK and Conservation International, Washington DC and Cambridge: Fauna \& Flora International; 2010.

[32] C. Susan, K. Honey, The Guinea Current LME Project: Results \& Status, IOCIUCN-NOAA Large Marine Ecosystem, 15th Consultative Committee Meeting, Paris, France, 11 July 2013.

[33] Duda A, Sherman K. A new imperative for improving management of large marine ecosystems. Ocean Coast. Manag. 2002;45:797-833.

[34] GEF Evaluation Office, GEF Annual Performance Report 2010, Evaluation Report no. 65, 2012.

[35] M. Tanstad, FAO-GEF Supported LME Projects, IOC-IUCN-NOAA Large Marine Ecosystems, 15th Consultative Committee Meeting, Paris, France, 11 July 2013.

[36] UNEP, Regional Oceans Governance-Making Regional Seas programmes, Regional Fishery Bodies and Large Marine Ecosystem Mechanisms Work Better Together, UNEP Regional Seas Report and Studies no. 195, 2015, in press.

[37] Freestone D, Johnson D, Ardron J, Morrison K, Unger S. Can existing institutions protect biodiversity in areas beyond national jurisdiction? Experiences from two on-going processes Mar. Policy 2014;49:167-75.

[38] Johnson DE. Can competent authorities cooperate for the common good: towards a collective arrangement in the North-East Atlantic. In: Berkman P, Vylegzhanin A, editors. Environmental Security in the Arctic Ocean. Dordrecht: Springer; 2013. p. 333-43.

[39] Olivier de Sardan J-P. Anthropologie et développement. Essai en socio-anthropologie du changement social. Paris: Karthala; 1995.

[40] OECD. Scaling-up finance Mechanisms for Biodiversity. Paris: OECD Publishing; 2013.

[41] Global Ocean Commission, From Decline to Recovery: A Rescue Package For the Global Ocean, 2014.

[42] Christie P, Pollnac RB, Fluharty DL, Hixon MA, Lowry GK, Mahon R, Pietri D, Tissot BN, White AT, Armada N, Eisma-Osorio R-L. Tropical marine EBM feasibility: a synthesis of case studies and comparative analyses. Coast. Manag. 2009:37(3):374-85.

[43] UNDP/GEF, Project Document, Strengthening Global Governance of Large Marine Ecosystems and Their Coasts through Enhanced Sharing and Application of LME/ICM/MPA Knowledge and Information Toolss, 2014. 